\title{
Apolipoprotein E epsilon-4 polymorphism is associated with younger age at referral to a lipidology clinic and a poorer response to lipid-lowering therapy
}

Rui Baptista ${ }^{1 *}$, Marta Rebelo², Joana Decq-Mota², Patrícia Dias², Pedro Monteiro', Luís A Providência ${ }^{2}$ and José M Silva²

\begin{abstract}
Background: The risk of coronary heart disease $(\mathrm{CHD})$ is related to environmental factors and genetic variants. Apolipoprotein E (apoE) polymorphisms are heritable determinants of total and low-density lipoprotein cholesterol, with some authors suggesting an association between the $\varepsilon 4$ allele and CHD. We investigated the relationship between apoE genotype and age at referral to a specialized lipid clinic by the primary care physician and whether the benefits of treatment with statin differed between genotypes.

Methods: We assessed individual apoE genotypes and lipid blood profile in a total of 463 patients followed at a specialized lipid clinic due to dyslipidemia, with a 3-year median follow-up time. The primary care physician at the time of the referral had no access to the apoE genotyping results. Carriers of apoE $\varepsilon 4 / \varepsilon 2$ genotype were excluded.

Results: The frequencies of $\varepsilon 2, \varepsilon 3$ and $\varepsilon 4$ alleles were $7.8,78.9$ and $13.3 \%$, respectively. There were no significant differences between genders. Although with similar lipid profiles and antidyslipidemic drug usage at baseline, $\varepsilon 4-$ carriers were referred to the clinic at a younger age (44.2 \pm 14.7 years) compared with non- $\varepsilon 4$ carriers (50.6 \pm 13.8 years) ( $p<0.001$ ), with a substantially younger age of referral for homozygous $E 4 / 4$ and for all genotypes with at least one copy of the $\varepsilon 4$ allele ( $p<0.001$ for trend). Although both $\varepsilon 4$ and non- $\varepsilon 4$ carriers achieved significant reductions in total cholesterol during follow-up ( $p<0.001 \mathrm{vs}$. baseline), the mean relative decrease in total cholesterol levels was higher in non- $\varepsilon 4$ carriers (-19.9 $\pm 2.3 \%)$ compared with $\varepsilon 4$ carriers $(-11.8 \pm 2.3 \%), p=0.003$.

Conclusion: Our findings support the concept that there is a reduced response to anti-dyslipidemic treatment in $\varepsilon 4$ carriers; this can be a contributing factor for the earlier referral of these patients to our specialized lipid clinic and reinforces the usefulness of apoE genotyping in predicting patients response to lipid lowering therapies.
\end{abstract}

\section{Background}

Coronary heart disease (CHD) is the main cause of mortality in developed countries. The risk of CHD may be influenced by environmental factors and genetic mutations in a number of genes controlling blood lipids and other risk factors. One of the most studied genes is the one coding for apolipoprotein $\mathrm{E}$ (apoE), located in chromosome 9 [1]. ApoE is a serum glycoprotein that plays

\footnotetext{
* Correspondence: ruibaptista@gmail.com

'Department of Cardiology, Coimbra Hospital and Medical School, Coimbra, Portugal

Full list of author information is available at the end of the article
}

a critical role in lipid metabolism [2]. It serves as a ligand for cell-surface receptor uptake of chylomicrons and very low-density lipoproteins (VLDL) on the liver [3] and controls intestinal cholesterol absorption[4].

A common polymorphism in the $A P O E$ gene (rs429358, rs7412) results in three isoforms called apoE2, apoE3 and apoE4, which are coded by three codominant alleles (designated as $\varepsilon 2, \varepsilon 3$ and $\varepsilon 4$ ), giving rise to six different genotypes [5]. The impact of apoE on plasma lipids is well known and may be partly related with increased CHD risk, with increasing plasma total cholesterol (TC) and low density lipoprotein (LDL)

\section{Ciomed Central}


cholesterol in the presence of the $\varepsilon 4$ allele [6-8]. However, the effect on HDL, apolipoprotein (apo) A or lipoprotein (Lp) (a) is less clear[9].

The results of epidemiologic studies examining the association between apoE genotypes and cardiovascular outcomes are inconsistent. Earlier data pointed to a clear gradient of risk conferred by the $\varepsilon 4$ allele, with ¿4-carriers particularly prone to develop disseminated coronary lesions, to be submitted to coronary revascularization procedures and to die from CHD [10-13]. However, these results have been questioned by Ward et $a l$., that found no association between apoE genotypes and CHD in a recent population study[14].

Based on this, the purpose of our investigation was (1) to determine the apoE genotype distribution and its association with plasma lipid traits in a population referred to a specialized lipid outpatient clinic, (2) to investigate whether the $\varepsilon 4$ allele influences the age of referral to the clinic, and if this was the case, (3) to assess if patients with the $\varepsilon 4$ allele were poorer responders to lipid-lowering therapeutic interventions.

\section{Methods}

\section{Study design and participants}

We conducted a retrospective observational study based on the analysis of the clinical records of 691 patients consecutively admitted and followed in a tertiary hospital specialized dyslipidemia outpatient clinic between January 1994 and October 2007. All patients were referred to consultation by their primary care physician or by other specialist within the hospital due to markedly abnormal, difficult to control lipid profile or due to suspected familial dyslipidemia. All patients were followed in either six-monthly or annual outpatient consultations, as decided appropriate by the attending physician, with regular assessment of laboratory and clinical parameters. All patients were treated to target the proposed LDL level recommended by the ATP III guidelines[15], by the use of dietary and pharmacological strategies. No formal recommendations were given regarding which type of drugs should be used for reaching the lipidic target. Apolipoprotein E genotypes were not taken in account when making therapeutic decisions regarding lipid-lowering drugs, as genotyping was performed solely with an investigational purpose. We conducted a 3-year follow-up analysis of blood lipids, namely TC, LDL, HDL and triglycerides. The study was approved by the local institutional board and all patients gave informed consent.

\section{Risk factors assessment}

Baseline, demographic and clinical variables are collected, including age at referral, gender, prior history of CHD, diabetes mellitus, smoking status, alcohol consumption, use of a salty diet and practice of exercise. Diabetes was defined as fasting glucose $\geq 126 \mathrm{mg} / \mathrm{dL}$ or use of hypoglycemic drugs and actual smoker if smoking one or more cigarettes per day in the last year. Alcohol consumption was positive in the patient consumed more than two units of alcoholic beverages per day. Use of a salty diet was considered if the patient added table salt to food. Regular exercise was defined by the performance of three or more periods of moderate exercise per week. On the first consultation, several baseline laboratory variables were obtained and a complete lipid profile was assayed by standard techniques in 12-h fasting blood samples, including TC, HDL, LDL, triglycerides, apoA and apoB and Lp(a) levels. Peripheral blood samples were obtained from each patient and dispatched immediately to analysis in our hospital central laboratory at $4^{\circ} \mathrm{C}$ before processing.

\section{DNA extraction and apoE genotyping}

DNA was extracted from whole-blood specimens according to standard procedures. Genomic DNA from these samples was analyzed for apoE polymorphisms (rs7412 and rs429358) using polymerase chain reaction and reverse hybridization; apoE concentrations were measured by nephelometry. Importantly, at the time of referral, no referring physician was aware of the apoE genotype of the patient, as these tests were only requested after this first medical contact in the hospital.

\section{Statistical analysis}

Allele frequencies were determined using the gene counting method. Hardy-Weinberg equilibrium for the distribution of the genotype was performed. Continuous variables were expressed as mean \pm SD. Median and interquartile range were used if the distribution was not normal, assessed by the use of the Kolmogorov-Smirnov test. The Student unpaired $\mathrm{t}$-test for normal variables and the Mann-Whitney $U$ test for non-normal variables were used for comparisons among groups. Paired-samples T-test was used for comparison between baseline and follow-up assessments. Categorical variables were presented as percentages, and were compared using $\chi 2$ or Fisher's exact test.

The number of patients in some individual genotype groups was too small to support group comparisons; therefore, and in a similar way to several other reports, we next compared patients with one or more copies of the $\varepsilon 4$ allele ( $\varepsilon 4$-carriers) to those without (non- $\varepsilon 4$ carriers). As in many other studies of this nature, eight subjects with the E4/2 genotype were excluded from the subsequent analyses since they could not be simply classified into any single allele group[14], because of the putative opposite effects of these two alleles in lipid levels. Plasma $\mathrm{Lp}(\mathrm{a})$ and triglycerides values were 
logarithmically transformed before all statistical analyses to improve the normality of the distributions. All statistical analyses were performed using SPSS 13.0 (Chicago, Illinois) with the level of significance set at $\mathrm{p}<0.05$.

\section{Results}

Of the 691 patients who were studied in the outpatient lipid consult, 228 were not genotyped, leaving a final sample with complete data for 463 patients, all Caucasian of Southern European ancestry. The observed distribution of apoE genotypes among patients, separately by man and women, is presented in Table 1 . The frequencies of $\varepsilon 2, \varepsilon 3$ and $\varepsilon 4$ alleles were $7.8,78.9$ and $13.3 \%$, respectively. Overall, 112 of 463 patients $(24.2 \%)$ were carriers of the $\varepsilon 4$ allele and 351 (75.8\%) were non\&4 carriers. The distribution of the apoE alleles was not in Hardy-Weinberg equilibrium. No significant differences were found among gender regarding the distribution of the alleles.

The apoE $\varepsilon 4$-carriers and non- $\varepsilon 4$ carriers groups were compared regarding demographic, clinical and laboratory variables (Table 2 and 3). The studied population had a small percentage of patients with prior CHD (4.2\%) but we found a significant proportion of diabetic patients $(24.9 \%)$. At baseline, no differences were found among patients with and without the $\varepsilon 4$ allele with regards to gender, smoking habits, alcohol consumption, exercise or use of a salty diet. Diabetes mellitus was less prevalent in patients with the $\varepsilon 4$ allele, but not reaching statistical significance $(20.5$ vs. $26.5 \%, p=0.286)$. No differences were found regarding aspirine, angiotensin receptor blockers, beta-blockers or calcium channel antagonists usage among groups. Angiotensinconverting enzyme inhibitors (ACEi) were used more frequently in non- $\varepsilon 4$ carriers; these patients also presented with higher blood pressure, although the average values were in the normal range $(135.6 \pm 21.0$ vs. 127.9

Table 1 Frequency of apoE genotype and apoE allele by gender

\begin{tabular}{lccc}
\hline & Total & Male & Female \\
\hline$N$ & 463 & 272 & 192 \\
Genotype & & & \\
E2/2 & $11(2.4 \%)$ & $7(2.6 \%)$ & $4(2.1 \%)$ \\
E3/2 & $42(9.1 \%)$ & $26(9.6 \%)$ & $16(8.3 \%)$ \\
E4/2 & $8(1.7 \%)$ & $4(1.5 \%)$ & $4(2.1 \%)$ \\
E3/3 & $298(64.2 \%)$ & $172(63.2 \%)$ & $126(65.6 \%)$ \\
E4/3 & $93(20.0 \%)$ & $56(20.6 \%)$ & $37(19.3 \%)$ \\
E4/4 & $11(2.6 \%)$ & $6(2.2 \%)$ & $5(2.7 \%)$ \\
Allele & & & \\
E2 & $7.8 \%$ & $8.1 \%$ & $7.3 \%$ \\
E3 & $78.9 \%$ & $78.6 \%$ & $79.4 \%$ \\
$\varepsilon 4$ & $13.3 \%$ & $13.3 \%$ & $13.3 \%$ \\
\hline
\end{tabular}

Table 2 Baseline characteristics of the $\mathbf{4 5 5}$ patients with different apoE alleles

\begin{tabular}{|c|c|c|c|c|}
\hline & Total & $\begin{array}{l}\text { Non- } 84 \\
\text { carriers }\end{array}$ & \&4 carriers & $\begin{array}{c}\mathrm{p}- \\
\text { value }\end{array}$ \\
\hline Age, years & $49.2 \pm 14.2$ & $50.6 \pm 13.8$ & $44.2 \pm 14.7$ & \\
\hline$<0.001$ & Men [n (\%)] & 267 (58.7\%) & $156(58.4 \%)$ & 159 \\
\hline (59.6\%) & 0.826 & & & \\
\hline $\mathrm{BMI}, \mathrm{kg} \cdot \mathrm{m}^{-2}$ & $28.1 \pm 4.7$ & $28.1 \pm 4.8$ & $28.1 \pm 4.1$ & 0.896 \\
\hline $\mathrm{SBP}, \mathrm{mmHg}$ & $133.8 \pm 20.5$ & $135.6 \pm 21$ & $127.9 \pm 17.6$ & 0.002 \\
\hline $\mathrm{DBP}, \mathrm{mmHg}$ & $83.5 \pm 11.7$ & $84.2 \pm 11.5$ & $80.9 \pm 12.1$ & 0.016 \\
\hline Heart rate, bpm & $73.4 \pm 12.3$ & $73.5 \pm 11.9$ & $73.3 \pm 13.8$ & 0.915 \\
\hline $\mathrm{TC}, \mathrm{mg} \cdot \mathrm{d} \ell^{-1}$ & $275.9 \pm 77.8$ & $277.8 \pm 81.3$ & $269.4 \pm 64.4$ & 0.338 \\
\hline $\mathrm{LDL}, \mathrm{mg} \cdot \mathrm{d} \ell^{-1}$ & $157.7 \pm 57.3$ & $157.6 \pm 58.5$ & $158.0 \pm 53.2$ & 0.956 \\
\hline $\mathrm{HDL}, \mathrm{mg}^{\mathrm{d}} \mathrm{l}^{-1}$ & $49.6 \pm 23.3$ & $49.9 \pm 24.9$ & $48.6 \pm 17.0$ & 0.618 \\
\hline $\begin{array}{l}\text { Triglycerides, mg. } \\
\qquad \ell^{-1}\end{array}$ & $\begin{array}{c}210 \\
(125-389)\end{array}$ & $218(127-381)$ & $\begin{array}{c}177 \\
(108-437)\end{array}$ & $0.535^{1}$ \\
\hline $\operatorname{Lp}(\mathrm{a})\left(\mathrm{mg} \cdot \mathrm{d} \ell^{-1}\right)$ & $15(6-37)$ & $15(6-37)$ & $14(6-36)$ & $0.815^{1}$ \\
\hline ApoE (mg.dl $\left.l^{-1}\right)$ & $6.8 \pm 5.9$ & $7.3 \pm 6.4$ & $5.3 \pm 3.0$ & 0.008 \\
\hline ApoB $\left(m g \cdot d l^{-1}\right)$ & $143.3 \pm 46.8$ & $145.7 \pm 49.3$ & $135.5 \pm 36.5$ & 0.062 \\
\hline ApoA $\left(m g \cdot d l^{-1}\right)$ & $152.4 \pm 32.9$ & $154 \pm 32.4$ & $146.8 \pm 33.9$ & 0.062 \\
\hline ApoB/ApoA & $0.98 \pm 0.36$ & $1.0 \pm 0.4$ & $1.0 \pm 0.3$ & 0.593 \\
\hline Creatinine, $\mathrm{mg}^{\mathrm{d} l^{-1}}$ & $0.96 \pm 0.49$ & $1.0 \pm 0.5$ & $0.9 \pm 0.3$ & 0.495 \\
\hline CK $\left(U . \ell^{-1}\right)$ & $\begin{array}{c}117.1 \pm \\
123.3\end{array}$ & $114.1 \pm 83.9$ & $\begin{array}{c}127.3 \pm \\
206.2\end{array}$ & 0.400 \\
\hline
\end{tabular}

${ }^{1}$ Comparisons for natural log-transformed variables. Values are median (interquartile range). BMI: body mass index. SBP: systolic blood pressure; DBP: diastolic blood pressure; TC: total cholesterol; LDL: low-density lipoprotein; HDL: high density lipoprotein; Lp(a): lipoprotein (a); Apo: apolipoprotein; CK: creatine kinase.

$\pm 17.6 \mathrm{mmHg}, \mathrm{p}=0.002$ ). Regarding prior antidyslipidemic drug usage, including statins and fibrates, no significant differences were found between $\varepsilon 4$ carriers and non- $\varepsilon 4$ carriers.

However, regarding age at referral to the lipid clinic, ع4-carriers were referred to hospital by their primary care physicians at significant younger ages than non- $\varepsilon 4$ carriers $(44.2 \pm 14.7$ vs. $50.6 \pm 13.8$ years, $\mathrm{p}<0.001)$. We also separated mean age at referral by genotype (Figure 1). The comparison of age at referral by the six apoE genotypes showed a significant effect, with a substantially younger age of referral for homozygous E4/4 and for all genotypes with at least one copy of the $\varepsilon 4$ allele ( $\mathrm{p}<0.001$ for trend). Interestingly, at baseline, $\varepsilon 4-$ carriers had similar lipid profiles compared with non- $\varepsilon 4$ carriers, independently of the fraction analyzed (TC, LDL, HDL, triglycerides, Lp(a), ApoA or ApoB). The only significant difference found in lipid profile was in apoE concentration with 84 -carriers having lower values as expected ( $5.3 \pm 3.0$ vs. $\left.7.3 \pm 6.4 \mathrm{mg} \cdot \mathrm{d} \ell^{-1}, \mathrm{p}=0.008\right)$. Other biochemical variables, as creatinine or creatine phosphokinase, as a marker of statin side effects, were similar among groups and with average values within the expected range. 
Table 3 Baseline prior history and medication of the 455 patients with different apoE alleles

\begin{tabular}{|c|c|c|c|c|c|}
\hline & Total & Non- $\varepsilon 4$ carriers & \&4 carriers & Odds-ratio $(95 \% \mathrm{Cl})$ & p-value \\
\hline \multicolumn{6}{|l|}{ Prior history } \\
\hline Diabetes mellitus & $24.9 \%$ & $26.3 \%$ & $20.5 \%$ & $0.723(0.398-1.313)$ & 0.285 \\
\hline Prior CHD & $4.2 \%$ & $4.9 \%$ & $2.4 \%$ & $0.478(0.105-2.179)$ & 0.330 \\
\hline Current smoker & $21.2 \%$ & $22.4 \%$ & $17.1 \%$ & $0.712(0.375-1.353)$ & 0.298 \\
\hline Alcohol consumption & $52.8 \%$ & $55.1 \%$ & $45.1 \%$ & $0.670(0.408-1.101)$ & 0.112 \\
\hline Regular exercise & $10.6 \%$ & $11.2 \%$ & $8.4 \%$ & $0.728(0.308-1.720)$ & 0.467 \\
\hline Use of a salty diet & $57.3 \%$ & $58.2 \%$ & $54.2 \%$ & $0.851(0.519-1.395)$ & 0.522 \\
\hline \multicolumn{6}{|l|}{ Prior medication } \\
\hline Aspirin & $41.8 \%$ & $44.5 \%$ & $32.9 \%$ & $0.612(0.357-1.048)$ & 0.072 \\
\hline Beta-blockers & $22.0 \%$ & $23.7 \%$ & $16.7 \%$ & $0.646(0.325-1.284)$ & 0.210 \\
\hline ACEi & $33.3 \%$ & $36.4 \%$ & $23.0 \%$ & $0.522(0.287-0.950)$ & 0.032 \\
\hline ARB & $21.3 \%$ & $21.9 \%$ & $19.2 \%$ & $0.817(0.415-1.607)$ & 0.614 \\
\hline Calcium antagonist & $19.2 \%$ & $19.9 \%$ & $16.9 \%$ & $0.817(0.415-1.607)$ & 0.557 \\
\hline Hypolipidemic drug* & $81.6 \%$ & $83.1 \%$ & $76.5 \%$ & $0.663(0.344-1.277)$ & 0.217 \\
\hline
\end{tabular}

ACEi: angiotensin converting enzime inhibitor: ARB: angiotensin receptor blocker * ${ }^{*}$ tatin or fibrate.

\section{Outpatient clinical follow-up}

All patients were followed in the specialized lipid clinic for a median period of 3 years (interquartile range, 1 to 6). During this period, a strategy was implemented in order to achieve the recommended ATP III goal levels of cholesterol in all patients. The variation in lipid profile is shown on Table 4. After the follow-up period, $57 \%$ of patients achieved a LDL value inferior to 130 mg.d $\ell^{-1}$ and $32 \%$ an LDL inferior to $100 \mathrm{mg} \cdot \mathrm{d}^{-1}$. The mean variation in TC was $-18.2 \%$, whereas $\mathrm{HDL}$ went up $11.1 \%$ and triglycerides were reduced by $-10.4 \%$ (all $\mathrm{p}<0.001$ vs. baseline values). Significant differences were found among $\varepsilon 4$-carriers and non- $\varepsilon 4$ carriers regarding the effectiveness of the therapeutic intervention. The proportion of patients reaching the LDL target level was lower in the $\varepsilon 4$-carriers and the absolute difference between $\mathrm{TC}$ at baseline and after therapeutic

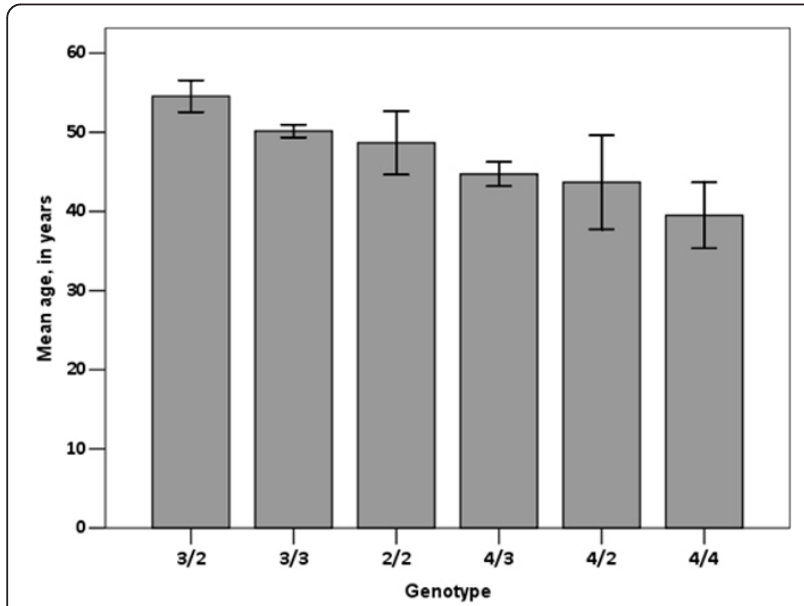

Figure 1 Mean age at referral for the specialized lipid clinic, by genotype. Bars are one standard error. $P<0.001$ for trend. intervention was $54.91 \pm 67.0 \mathrm{mg} \cdot \mathrm{d} \ell^{-1}$ in the $\varepsilon 4$ carriers, compared with $78.8 \pm 66.9 \mathrm{mg} \cdot \mathrm{d} \ell^{-1}$ in the $\varepsilon 4$-non carriers $(\mathrm{p}<0.05)$. This correlates with an inferior relative reduction in $\mathrm{TC}$ within $\varepsilon 4$-carriers than in $\varepsilon 4$-non carriers $(-11.8 \pm 2.3 \%$ vs. $-19.9 \pm 2.3 \%, \mathrm{p}=0.003)$. The same was true for the other lipid subfractions, but without reaching statistical significance (Figure 2).

\section{Discussion}

To our knowledge this is the first study to examine the association between apoE genotypes and age at referral to a specialized lipid clinic. We demonstrate that patients carrying one or more copies of the $\varepsilon 4$ allele are referred at significantly younger ages to the lipid clinic and after a mean follow-up of three years these patients have a poorer response to treatment.

We observed overall that the $\varepsilon 3$ allele was the most frequent, followed by the $\varepsilon 4$ allele and $\varepsilon 2$ allele. This finding is ubiquitous for human populations [9]. In Europe, the frequency of apoE genotypes demonstrates a North-South gradient, with a progressive decline in the $\varepsilon 4$ allele frequency from Northern (14-19\%) to Southern

Table 4 Follow-up lipid profile of patients

\begin{tabular}{lcccc}
\hline & Total & Non- 8 carriers & $\boldsymbol{\varepsilon} 4$ carriers & p-value \\
\hline $\mathrm{LDL}<130$ & 57.2 & 61.4 & 43.2 & 0.002 \\
$\mathrm{mg} \cdot \mathrm{d \ell ^{-1 }}(\%)$ & & & & \\
$\mathrm{LDL}<100$ & 32.4 & 34.9 & 23.9 & 0.052 \\
$\mathrm{mg} \cdot \mathrm{dl^{-1 }}(\%)$ & & & & \\
$\mathrm{TC}$ variation (\%) & $-18.2 \pm 2.3$ & $-19.9 \pm 2.3$ & $-11.8 \pm 2.3$ & 0.003 \\
$\mathrm{LDL}$ variation (\%) & $-16.0 \pm 4.7$ & $-17.9 \pm 4.9$ & $-9.5 \pm 4.3$ & $0.068^{1}$ \\
$\mathrm{HDL}$ variation (\%) & $+11.1 \pm 4.3$ & $+11.7 \pm 4.7$ & $+7.1 \pm 2.6$ & $0.379^{1}$ \\
Triglyceride & $-10.4 \pm 8.5$ & $-11.3 \pm 8.7$ & $-4.6 \pm 7.8$ & $0.508^{1}$ \\
variation (\%) & & & & \\
\hline
\end{tabular}

${ }^{1}$ Mann-Whintey test. TC: total cholesterol; LDL: low-density lipoprotein; HDL: high density lipoprotein; TG: triglyceride. 


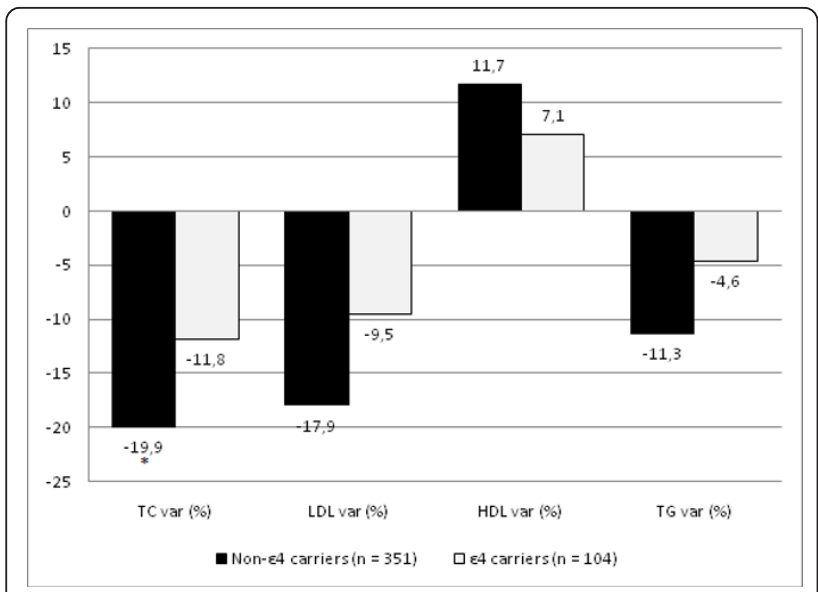

Figure 2 Three-year follow-up variation in lipid levels, by $\mathbf{\varepsilon} 4-$ carrier status. TC: total cholesterol; LDL: low-density lipoprotein; HDL: high density lipoprotein; TG: triglyceride; var: variation. * $P<0.05$

Europe (7-12\%) [16]. In our population the frequency of the $\varepsilon 4$ allele was $13.3 \%$, a value that is closer to the one found in populations from Northern Europe and in clear excess of the expected frequency of the $\varepsilon 4$ allele in the Portuguese healthy population (9.0\%), one of the lowest reported in Europe [7]. This disequilibrium might be explained by the referred nature of our population, although that fact is not obvious by the lipid concentrations, as there are no significant differences among groups at baseline. Regarding the E2/2 genotype, there is also a higher frequency (2.2\%) than expected for the Portuguese population (0.3\%)[7], probably due to the inclusion of some cases of hyperlipoproteinemia type III[17].

ApoE $\varepsilon 4$ allele has been linked to higher total and LDL cholesterol plasma levels in several studies[7]. However, this was not the case in our population, where we found no significant association between $\varepsilon 4$-carrier status and baseline TC and LDL. The associations between the apoE polymorphism and plasma concentrations of HDL, apoA, Lp(a) and triglycerides have been more inconsistent in the literature, with results that range from no association $[18,19]$ to associations that vary by sex [20]. We found no association between those lipid traits and ع4-carrier status in our population. We also found, as expected, that $\varepsilon 4$-carriers had lower plasma concentrations of apoE, compared with $\varepsilon 4$-non carriers. It has been suggested that high apoE plasma levels have prognostic impact, independent of apoE genotypes, lipid values and other cardiovascular risk factors $[7,21]$. Further research is needed to clarify to role of apoE concentration in the assessment of global cardiovascular risk.
As reported by Chiodoni et al.[22], we found a nonsignificant trend of a lower prevalence of diabetic patients in $\varepsilon 4$-carriers compared with the non- $\varepsilon 4$ carriers, this disease being highly prevalent in our cohort (21.1\%). This can be due to the younger age of presentation of the $\varepsilon 4$-carriers or to a distinctive effect of the $\varepsilon 4$ allele on carbohydrate metabolism that remains to be elucidated.

Although no differences were found in lipid profiles among $\varepsilon 4$-carriers and non-carriers, the former were consistently referred at younger ages to the lipid clinic, with a clear and significant gradient to patients with more copies of the $\varepsilon 4$ allele being referred at proportionally younger ages. What alerted the primary care physicians to refer such patients at younger ages?

Several reports studied the interaction between age, apoE and target organ disease. Newman et al. demonstrates a significant trend for early coronary revascularization surgery for patients with higher number of copies of the $\varepsilon 4$ allele, compared with $\varepsilon 3$ and $\varepsilon 2$ carriers[12]. Other studies have also indicated a substantial (16-fold) increase in the prevalence of the $\varepsilon 4$ allele in patients referred for coronary angioplasty[23] and its predictive power regarding coronary vessel restenosis [24]. In our population, although not having a higher incidence of prior CHD, \&4-carriers could have presented with more intense abnormalities in lipid profile than expected at younger ages to their primary care physicians, prompting the referral to the hospital.

Other factor that may have been implicated in early referral was the level of response to lipid-lowering therapy. During follow-up, the TC of our patients was lowered in average 18\%, the LDL-C 16\% and TG 10\% and HDL was improved on average $11 \%$. These results compare with those from the GISSI-Prevenzione (GISSIP) study, also conducted in a Southern European population and that obtained at a mean follow-up time of 24 months similar reductions in the lipid profile with the use of pravastatin (20 to $40 \mathrm{mg}$ ) [25]. We report a lower variation in TC in $\varepsilon 4$-carriers compared to non- $\varepsilon 4$ carriers, with both groups under a similar hypolipidemic strategy $(-19.9 \pm 2.3$ vs. $-11.8 \pm 2.3 \%, p=0.003)$. In fact, although departing from slightly lower TC levels, $\varepsilon 4-$ carriers reached the end the follow-up period with higher TC levels than non- $\varepsilon 4$ carriers and with a higher proportion of patients with LDL over $130 \mathrm{mg} \cdot \mathrm{dl}^{-1}$.

The effect of the apoE genotype on antidyslipidemic drugs' efficacy, namely statins, has been thoroughly studied in the last years[26]. Although several efforts have been made to identify genes that might be involved in statin response, a recent analysis for the Treating to New Targets (TNT) study concluded that, after analyzing almost 300,000 putative sites, only polymorphisms in the apoE gene were found to influence statin 
response significantly, highlighting the pivotal role of this gene on lipid metabolism. In this genome-wide study, patients with apoE 4/4 allele had a lower response to atorvastatin treatment than patients with E3/3 allele regarding LDL levels (37.7 vs. 40.3\%) [27]. Taken together, the majority of studies indicate that patients with the $\varepsilon 4$ allele seem to have the poorest and those with the $\varepsilon 2$ allele the strongest response to statins regarding LDL lowering [28-31]; in addition, $\varepsilon 2$ carriers may reach the LDL treatment goals more frequently than $\varepsilon 4$ carriers [32]. These findings have not been reproduced by other authors [33-35]. In a subanalysis of the GISSI-P study, only carriers of the considered highrisk $\varepsilon 4$ allele seemed to benefit from the treatment with statin, regarding mortality [22], corroborating the findings of the $4 \mathrm{~S}$ subanalysis, where the treatment with simvastatin neutralized the higher risk of mortality of $\varepsilon 4$ carriers[33]. This fact should alert physicians to aggressively treat to target lipid goals in these patients.

Our population was selected by primary care physicians for follow-up at a specialized lipid clinic and does not represent a cross-section of the population as a whole; however, based on cardiovascular risk factors, our population reflects the usual adult population seen in a primary care setting. The reported disequilibrium in genotype frequencies compared to those expected in a non-selected healthy population reflects the referral nature of our population. Numerous factors may have guided the decision to refer to lipid clinic and we can only speculate on what those factors may be. However, the fact remains that in the population studied, there was a distinct association between the presence of the apoE $\varepsilon 4$ allele and an earlier presentation for tertiary specialized lipid care. We also demonstrate that after a mean follow-up of three years, the impact of therapeutics in the level of TC was significantly lower in \&4-carriers. One may hypothesize that, although having similar lipid levels at baseline compared with non- $\varepsilon 4$ carriers, the combination of a more severe lipid profile at younger ages with a poorer response to an already initiated standard hypolipidemic therapy may all had a role in the decision of the primary care physician to refer these patients. We must highlight that primary care physicians were blinded to apoE genotypes, as genotyping was performed only at the hospital.

The study has some limitations. The inclusion of participants receiving medication for $\mathrm{CHD}$, diabetes, hypertension or hypercholesterolemia can alter physiologic lipid levels and confound the lipid associations. However, no differences were found regarding the frequency of usage of these medications in primary care between groups, except for ACEi. Moreover, as the primary care physicians were not aware of the genotypes, the referral was made in an entirely blinded fashion. The inexistence of a defined protocol for statin use during follow-up time in the specialized lipid consultation is compensated by the fact that no differences were found on lipid-lowering therapies management on both groups.

\section{Conclusions}

In conclusion, we have demonstrated that the presence of the apoE $\varepsilon 4$ allele is associated with referral at younger ages to a specialized lipid clinic, although no differences were found regarding baseline lipid profile that could account for such earlier referrals. Moreover, these patients had a poorer response to the antidyslipidemic treatment instituted during the follow up period. Intensive therapeutical strategies must be followed to achieve the recommended target goals of lipid levels, particularly in high-risk patients as 84 -carriers. Our findings suggest that pharmacogenomics could be considered for individualized tailoring of global cardiovascular risk assessment strategies.

\section{Author details}

'Department of Cardiology, Coimbra Hospital and Medical School, Coimbra, Portugal. ${ }^{2}$ Department of Internal Medicine, Coimbra Hospital and Medical School, Coimbra, Portugal.

\section{Authors' contributions}

$\mathrm{RB}$ conceived the study, participated in the design of the study, acquired data and performed the statistical analysis. MR participated in the design of the study and acquired data. JDM participated in the design of the study and acquired data. PD participated in the design of the study and its coordination. PM revised the manuscript for important intellectual content. LAP revised the manuscript for important intellectual content. JMS conceived the study, participated in the design of the study and revised the manuscript for important intellectual content.

All authors read and approved the final manuscript.

\section{Competing interests}

The authors declare that they have no competing interests.

Received: 28 January 2011 Accepted: 30 March 2011

Published: 30 March 2011

\section{References}

1. Davignon J, Gregg RE, Sing CF: Apolipoprotein E polymorphism and atherosclerosis. Arteriosclerosis 1988, 8:1-21.

2. Kolovou GD, Anagnostopoulou KK: Apolipoprotein E polymorphism, age and coronary heart disease. Ageing Res Rev 2007, 6:94-108.

3. Anoop S, Misra A, Meena K, Luthra K: Apolipoprotein E polymorphism in cerebrovascular \& coronary heart diseases. Indian J Med Res 2010, 132:363-378.

4. Kesaniemi YA, Ehnholm C, Miettinen TA: Intestinal cholesterol absorption efficiency in man is related to apoprotein E phenotype. J Clin Invest 1987, 80:578-581.

5. Mahley RW, Rall SC Jr: Apolipoprotein E: far more than a lipid transport protein. Annu Rev Genomics Hum Genet 2000, 1:507-537.

6. Lehtinen S, Lehtimaki T, Sisto T, Salenius JP, Nikkila M, Jokela H, Koivula T, Ebeling F, Ehnholm C: Apolipoprotein E polymorphism, serum lipids, myocardial infarction and severity of angiographically verified coronary artery disease in men and women. Atherosclerosis 1995, 114:83-91.

7. Haddy N, De Bacquer D, Chemaly MM, Maurice M, Ehnholm C, Evans A, Sans S, Do Carmo Martins M, De Backer G, Siest G, Visvikis S: The importance of plasma apolipoprotein $E$ concentration in addition to its 
common polymorphism on inter-individual variation in lipid levels: results from Apo Europe. Eur J Hum Genet 2002, 10:841-850.

8. Alvim RO, Freitas $S R$, Ferreira NE, Santos PC, Cunha RS, Mill JG, Krieger JE, Pereira AC: APOE polymorphism is associated with lipid profile, but not with arterial stiffness in the general population. Lipids Health Dis 2010 9:128.

9. Burman D, Mente A, Hegele RA, Islam S, Yusuf S, Anand SS: Relationship of the ApoE polymorphism to plasma lipid traits among South Asians, Chinese, and Europeans living in Canada. Atherosclerosis 2009, 203:192-200

10. Eichner JE, Kuller LH, Orchard TJ, Grandits GA, McCallum LM, Ferrell RE, Neaton JD: Relation of apolipoprotein E phenotype to myocardial infarction and mortality from coronary artery disease. Am J Cardiol 1993, 71:160-165.

11. Stengard JH, Zerba KE, Pekkanen J, Ehnholm C, Nissinen A, Sing CF: Apolipoprotein E polymorphism predicts death from coronary heart disease in a longitudinal study of elderly Finnish men. Circulation 1995, 91:265-269.

12. Newman MF, Laskowitz DT, White WD, Kirchner JL, Grocott HP, StaffordSmith M, Sketch MH, Jones RH, Reves JG, Saunders AM: Apolipoprotein E polymorphisms and age at first coronary artery bypass graft. Anesth Analg 2001, 92:824-829.

13. Bennet AM, Di Angelantonio E, Ye Z, Wensley F, Dahlin A, Ahlbom A, Keavney B, Collins R, Wiman B, de Faire U, Danesh J: Association of apolipoprotein $\mathrm{E}$ genotypes with lipid levels and coronary risk. JAMA 2007, 298:1300-1311.

14. Ward H, Mitrou PN, Bowman R, Luben R, Wareham NJ, Khaw KT, Bingham S: APOE genotype, lipids, and coronary heart disease risk: a prospective population study. Arch Intern Med 2009, 169:1424-1429.

15. Third Report of the National Cholesterol Education Program (NCEP) Expert Panel on Detection, Evaluation, and Treatment of High Blood Cholesterol in Adults (Adult Treatment Panel III) final report. Circulation 2002, 106:3143-3421

16. Eichner JE, Dunn ST, Perveen G, Thompson DM, Stewart KE, Stroehla BC Apolipoprotein E polymorphism and cardiovascular disease: a HuGE review. Am J Epidemiol 2002, 155:487-495.

17. Smelt $A H$, de Beer F: Apolipoprotein $E$ and familial dysbetalipoproteinemia: clinical, biochemical, and genetic aspects. Semin Vasc Med 2004, 4:249-257.

18. Anuurad E, Lu G, Rubin J, Pearson TA, Berglund $L:$ ApoE genotype affects allele-specific apo[a] levels for large apo[a] sizes in African Americans: the Harlem-Basset Study. J Lipid Res 2007, 48:693-698.

19. de Knijff $P$, Kaptein A, Boomsma D, Princen HM, Frants RR, Havekes LM: Apolipoprotein E polymorphism affects plasma levels of lipoprotein(a). Atherosclerosis 1991, 90:169-174.

20. Frikke-Schmidt R, Nordestgaard BG, Agerholm-Larsen B, Schnohr P, Tybjaerg-Hansen A: Context-dependent and invariant associations between lipids, lipoproteins, and apolipoproteins and apolipoprotein $E$ genotype. J Lipid Res 2000, 41:1812-1822.

21. Mooijaart SP, Berbee JF, van Heemst D, Havekes LM, de Craen AJ, Slagboom PE, Rensen PC, Westendorp RG: ApoE plasma levels and risk of cardiovascular mortality in old age. PLoS Med 2006, 3:e176.

22. Chiodini BD, Franzosi MG, Barlera S, Signorini S, Lewis CM, D'Orazio A, Mocarelli P, Nicolis E, Marchioli R, Tognoni G: Apolipoprotein E polymorphisms influence effect of pravastatin on survival after myocardial infarction in a Mediterranean population: the GISSIPrevenzione study. Eur Heart J 2007, 28:1977-1983.

23. van Bockxmeer FM, Mamotte CD: Apolipoprotein epsilon 4 homozygosity in young men with coronary heart disease. Lancet 1992, 340:879-880.

24. van Bockxmeer FM, Mamotte CD, Gibbons FR, Taylor RR: Apolipoprotein epsilon 4 homozygosity-a determinant of restenosis after coronary angioplasty. Atherosclerosis 1994, 110:195-202.

25. Results of the low-dose $(20 \mathrm{mg})$ pravastatin GISSI Prevenzione trial in 4271 patients with recent myocardial infarction: do stopped trials contribute to overall knowledge? GISSI Prevenzione Investigators (Gruppo Italiano per lo Studio della Sopravvivenza nell'Infarto Miocardico). Ital Heart J 2000, 1:810-820.

26. Nieminen $T$, Kahonen $M$, Viri LE, Gronroos $P$, Lehtimaki T: Pharmacogenetics of apolipoprotein $\mathrm{E}$ gene during lipid-lowering therapy: lipid levels and prevention of coronary heart disease. Pharmacogenomics 2008, 9:1475-1486.
27. Thompson JF, Hyde CL, Wood LS, Paciga SA, Hinds DA, Cox DR, Hovingh GK, Kastelein JJ: Comprehensive whole-genome and candidate gene analysis for response to statin therapy in the Treating to New Targets (TNT) cohort. Circ Cardiovasc Genet 2009, 2:173-181.

28. Ballantyne CM, Herd JA, Stein EA, Ferlic LL, Dunn JK, Gotto AM Jr, Marian AJ: Apolipoprotein E genotypes and response of plasma lipids and progression-regression of coronary atherosclerosis to lipid-lowering drug therapy. J Am Coll Cardiol 2000, 36:1572-1578.

29. Nestel P, Simons L, Barter P, Clifton P, Colquhoun D, Hamilton-Craig I, Sikaris K, Sullivan D: A comparative study of the efficacy of simvastatin and gemfibrozil in combined hyperlipoproteinemia: prediction of response by baseline lipids, apo E genotype, lipoprotein(a) and insulin. Atherosclerosis 1997, 129:231-239.

30. Ojala JP, Helve E, Ehnholm C, Aalto-Setala K, Kontula KK, Tikkanen MJ: Effect of apolipoprotein E polymorphism and Xbal polymorphism of apolipoprotein B on response to lovastatin treatment in familial and non-familial hypercholesterolaemia. J Intern Med 1991, 230:397-405.

31. Ordovas JM, Lopez-Miranda J, Perez-Jimenez F, Rodriguez C, Park JS, Cole T, Schaefer EJ: Effect of apolipoprotein E and A-IV phenotypes on the low density lipoprotein response to HMG CoA reductase inhibitor therapy. Atherosclerosis 1995, 113:157-166.

32. Donnelly LA, Palmer CN, Whitley AL, Lang CC, Doney AS, Morris AD, Donnan PT: Apolipoprotein E genotypes are associated with lipidlowering responses to statin treatment in diabetes: a Go-DARTS study. Pharmacogenet Genomics 2008, 18:279-287.

33. Gerdes LU, Gerdes C, Kervinen K, Savolainen M, Klausen IC, Hansen PS, Kesaniemi YA, Faergeman O: The apolipoprotein epsilon4 allele determines prognosis and the effect on prognosis of simvastatin in survivors of myocardial infarction: a substudy of the Scandinavian simvastatin survival study. Circulation 2000, 101:1366-1371.

34. Sanllehy C, Casals E, Rodriguez-Villar C, Zambon D, Ojuel J, Ballesta AM, Ros E: Lack of interaction of apolipoprotein E phenotype with the lipoprotein response to lovastatin or gemfibrozil in patients with primary hypercholesterolemia. Metabolism 1998, 47:560-565.

35. Pena R, Lahoz C, Mostaza JM, Jimenez J, Subirats E, Pinto X, Taboada M, Lopez-Pastor A: Effect of apoE genotype on the hypolipidaemic response to pravastatin in an outpatient setting. J Intern Med 2002, 251:518-525.

doi:10.1186/1476-511X-10-48

Cite this article as: Baptista et al:: Apolipoprotein E epsilon-4 polymorphism is associated with younger age at referral to a lipidology clinic and a poorer response to lipid-lowering therapy. Lipids in Health and Disease 2011 10:48.

\section{Submit your next manuscript to BioMed Central and take full advantage of:}

- Convenient online submission

- Thorough peer review

- No space constraints or color figure charges

- Immediate publication on acceptance

- Inclusion in PubMed, CAS, Scopus and Google Scholar

- Research which is freely available for redistribution 